CLINICAL STUDY

\title{
The impact of medication on vitamin D status in older individuals
}

\author{
E Sohl, N M van Schoor, R T de Jongh ${ }^{1}$, O J de Vries ${ }^{2}$ and P Lips ${ }^{1}$ \\ Department of Epidemiology and Biostatistics, EMGO Institute for Health and Care Research, VU University Medical Center, Van der Boechorststraat 7 , \\ Room A517, 1081 BT Amsterdam, The Netherlands, Departments of ${ }^{1}$ Endocrinology and ${ }^{2}$ Internal Medicine, VU University Medical Center, PO Box \\ 7057, 1007 MB Amsterdam, The Netherlands \\ (Correspondence should be addressed to N M van Schoor; Email: nm.vanschoor@vumc.nl)
}

\begin{abstract}
Objective: Vitamin D deficiency and polypharmacy are common in the elderly. However, knowledge on the associations between the use of specific medicines and serum 25-hydroxyvitamin $\mathrm{D}(25(\mathrm{OH}) \mathrm{D})$ is limited. The aim of this study was to (better) define the associations between the use of specific medicines and serum 25(OH)D.

Methods: Two different cohorts (1995/1996 and 2002/2003) from the Longitudinal Aging Study Amsterdam (LASA) were used for cross-sectional analyses. LASA is based on an age and sex-stratified random sample of the Dutch older population. Study participants were aged 65-88 years in the first cohort $(n=1301)$ and 55-65 years in the second cohort $(n=736)$. Serum 25(OH)D of users of several groups of medicines were compared with levels of non-users using multiple linear regression analysis. Results: Of all participants, $75.4 \%$ (first cohort) and $61.1 \%$ (second cohort) were using at least one medicine. In both cohorts, the number of medicines was associated with lower serum $25(\mathrm{OH}) \mathrm{D}$. In the first cohort, after adjustment for confounding, users of any kind of medicine, loop diuretics and inhaled corticosteroids (only men) had respectively $4.4 \mathrm{nmol} / \mathrm{l}(P<0.01), 4.7 \mathrm{nmol} / \mathrm{l}(P=0.04)$ and $7.3 \mathrm{nmol} / \mathrm{l}(P=0.02)$ lower serum $25(\mathrm{OH}) \mathrm{D}$ than non-users. In the second cohort, the use of oral antidiabetics, calcium-channel blockers and angiotensin-converting enzyme inhibitors was associated with respectively $7.4 \mathrm{nmol} / \mathrm{l}(P=0.04), 7.7 \mathrm{nmol} / \mathrm{l}(P=0.01)$ and $7.6 \mathrm{nmol} / \mathrm{l}(P<0.01)$ lower serum 25(OH)D.

Conclusions: These data show that users of several medicines have lower serum 25(OH)D than nonusers. Vitamin D supplementation may be considered in patients with chronic use of medicines.
\end{abstract}

European Journal of Endocrinology 166 477-485

\section{Introduction}

Vitamin D deficiency is common in older individuals. Depending on country and used definition, the prevalence of vitamin $\mathrm{D}$ deficiency in the older Western population ranges from 0 up to $90 \%$ (1). Low serum 25-hydroxyvitamin D $(25(\mathrm{OH}) \mathrm{D})$ in the elderly is caused by a less efficient vitamin $\mathrm{D}$ production in the skin, low sunshine exposure and low dietary intake $(1,2)$.

Older individuals often suffer from chronic diseases (3), prompting the frequent use of medication. Previous research, performed in the United States, demonstrated that $23 \%$ of women and $19 \%$ of men took five or more prescription medicines. In addition, rates of use were increasing with advancing age (4). In the Netherlands, individuals of 75 years and older use five times as much medication as the average Dutch person (5).

As stated above, low serum $25(\mathrm{OH}) \mathrm{D}$ as well as polypharmacy is common in older individuals. To our knowledge, information about the influence of medicines on serum $25(\mathrm{OH}) \mathrm{D}$ is limited. For example, some statins
$(6,7,8)$ are found to elevate serum $25(\mathrm{OH}) \mathrm{D}$, whereas anti-epileptic drugs lower serum 25(OH)D $(9,10)$. Further knowledge about associations is warranted, because of the large influence of vitamin D in several physiological processes (1) and the possibility to prescribe vitamin D supplements in case of a lowering effect.

The aim of this study was to determine whether frequently used medicines are associated with serum $25(\mathrm{OH}) \mathrm{D}$ in older individuals. The analyses were performed with data derived from the Longitudinal Aging Study Amsterdam (LASA), an ongoing cohort study of Dutch older individuals.

\section{Subjects and methods}

\section{Study participants}

Data for this study were collected in the ongoing LASA. LASA is a prospective Dutch cohort study of older individuals, aged 55-85 years at the start in 1992 . 
The sampling and data collection procedures and non-response data are described elsewhere in detail $(11,12)$. Briefly, a random sample of men and women, stratified by age, sex and expected five-year mortality rate, was drawn from population registers from eleven municipalities (in three geographical regions) in the Netherlands. At baseline 3107 subjects aged 55-85 years were enrolled, and in 2002 an additional cohort was recruited which consisted of 1002 subjects aged 55-65 years. The study was approved by the Medical Ethics Committee of the VU University Medical Center and all participants gave informed consent.

For the present study, data from the second measurement cycle of the first cohort (1995/1996) and from the first measurement cycle of the second cohort (2002/2003) were used. In the first cohort, persons who participated in the medical interview in 1995/1996, born in or before 1930 (aged 65 years and older as of January 1,1996$)$, were selected $(n=1509)$. In 1352 of these persons, blood samples were drawn and serum 25(OH)D could be determined in 1320 samples. After exclusion due to missing values for potential confounders $(n=19)$, the study sample consisted of 1301 subjects.

In the second cohort, 919 subjects completed the medical interview. Blood samples were drawn from 747 persons and serum $25(\mathrm{OH}) \mathrm{D}$ could be determined in 739 persons. After exclusion due to missing values for potential confounders or medication use $(n=3)$, the study sample consisted of 736 subjects.

\section{Serum 25(OH)D}

Morning blood samples were obtained in 1995/1996 and in 2002/2003. Subjects were only allowed to take tea and toast, but no dairy products. The samples were centrifuged and stored at $-20{ }^{\circ} \mathrm{C}$ until determination. For the samples from 1995/1996 serum 25(OH)D was measured in 1997/1998, and for the samples from $2002 / 2003$ measurement took place in 2009. For both analyses, a competitive protein binding assay was used (1997/1998: Nichols Diagnostics, San Juan Capistrano, CA, USA; 2009: Diasorin, Stillwater, MN, USA). The inter-assay coefficients of variation values were $10 \%$ for both methods. The Nichols and Diasorin assays were compared by measuring 117 samples (41 LASA participants, and 76 patient samples, measured for clinical purposes) with both methods (range from $<5$ to $123 \mathrm{nmol} / \mathrm{l})$. This cross-calibration showed that levels of 25,50 and $75 \mathrm{nmol} / \mathrm{l}$ measured with the Nichols device equaled 26.0, 48.2 and $70.4 \mathrm{nmol} / \mathrm{l}$ respectively when measured with the Diasorin device. The correlation coefficient was $r=0.94$. For this study, original non-calibrated values were used.

All analyses were performed in the Endocrine Laboratory of the VU University Medical Center.

\section{Medication use}

Medication use was assessed during the medical interview. Participants were asked to show their medication containers to the interviewers. The medication names were recoded into ATC codes using the ATC index from the World Health Organization. These ATC codes were used to create groups of users of specific groups of medicines (13).

\section{Potential effect modifier}

Gender was examined as a potential effect modifier. This was done because gender is known to be important in pharmacokinetics and pharmacodynamics due to differences in, for example, hepatic and renal processes (14).

\section{Potential confounders}

The following potential confounders were included in the statistical analyses: age, gender, number of chronic diseases, body mass index (BMI), smoking, alcohol use, education level, season of blood collection, albumin, estimate of renal function (modification of diet in renal diseases (MDRD)) and physical activity.

The number of chronic diseases was obtained by selfreport, using questions on seven major diseases: chronic obstructive pulmonary disease, cardiac disease, peripheral arterial disease, diabetes mellitus, stroke, cancer and rheumatoid arthritis/osteoarthritis. BMI was calculated as body weight in kilograms divided by height in square meters and subsequently it was categorised into three groups: underweight (BMI $<20 \mathrm{~kg} / \mathrm{m}^{2}$ ), normal weight $\left(\mathrm{BMI} \geq 20 \mathrm{~kg} / \mathrm{m}^{2}\right.$ ) and overweight (BMI $\left.\geq 25 \mathrm{~kg} / \mathrm{m}^{2}\right)$. Body weight was measured without clothes and shoes using a calibrated balance scale. Body height was measured using a stadiometer. Smoking (never, former and current smoker) and alcohol consumption (non, light, moderate and (very) excessive drinker) were based on self-report. Classification of alcohol use was based on the number of days per week alcohol was consumed and the number of drinks per time (15).

Education level was converted into years of education, and subsequently it was dichotomised into two categories: low level ( $\leq 9$ years) and high level $(>9$ years). Serum albumin was measured using a photometric assay in three different laboratories (one in each region). MDRD was calculated from serum creatinine (measured using Hitachi 747 analyzer), using the following formula: $186(\mathrm{creatinine}(\mu \mathrm{mol} / \mathrm{l}) / 88.4)^{-1.154}$ $\times$ age (years) $)^{-0.203} \times(0.742$ if woman) (16). Season of blood collection was dichotomised into summer (AprilSeptember) and winter (October-March). Physical activity was assessed using the LASA Physical Activity Questionnaire, a validated interviewer-administered questionnaire about the duration and frequency of activities during the past 2 weeks (17). 


\section{Statistical analysis}

Analyses were performed if the user group consisted of $\geq 5 \%$ of the study sample. Multiple linear regression analysis was used to examine differences in serum $25(\mathrm{OH}) \mathrm{D}$ between medication users and non-users. Assumptions of linear regression analysis were tested by normal probability plots and histograms. To test for interaction with gender, $P$ value $<0.1$ was considered as statistically significant. When considered significant, further analyses were performed in subgroups. To check for confounding, all potential confounders were added one by one to the univariable model. Parameters which gave a change in regression coefficient (unstandardised beta $(B)$ ) of more than $10 \%$ were added to the model. After this procedure, we created three models with the most relevant confounders. The first model adjusted for age and gender. The second model additionally adjusted for chronic diseases. The third model further adjusted for BMI, MDRD, albumin, smoking, alcohol use and season of blood collection. For all models $P<0.05$ was considered as significant. To further demonstrate differences in age, an additional analysis was performed in subgroups in the first cohort (divided by the median age, 75 years). Because we did not have data on vitamin D supplementation, sensitivity analyses were performed using the fully adjusted models, in which we added multi-vitamin use as an additional confounder in the first cohort. In the second cohort, data on multi-vitamin use were not available. Physical activity was added separately to the third model to determine whether it was a mediator or a confounder. All analyses were performed using SPSS version 15.0 for Windows (SPSS Inc., Chicago, IL, USA).

\section{Results}

In the first cohort (1995/1996) a total of 1301 participants ( 634 men, 667 women) and in the second cohort (2002/2003) 737 participants (338 men, 399 women) were included in the analyses. Table 1 shows the characteristics of the study population. Owing to inclusion criteria with regard to age $(65+$ in first cohort; 55-65 years in second cohort) participants of the first cohort were much older than the participants of the second cohort (mean age 75.5 (s.D. 6.6) vs 60.0 (s.D. 2.9) years). The mean serum $25(\mathrm{OH}) \mathrm{D}$ was 53.4 (s.D. 24.1) $\mathrm{nmol} / \mathrm{l}$ in the first cohort and 56.7 (s.D. 20.7) $\mathrm{nmol} / \mathrm{l}$ in the second cohort. In the two cohorts, $11.1 \%$ (first cohort) and $3.4 \%$ (second cohort) of the participants had serum 25(OH)D below $25 \mathrm{nmol} / \mathrm{l}$; and $48.3 \%$ (first cohort) and 40.5\% (second cohort) had serum 25(OH)D below $50 \mathrm{nmol} / \mathrm{l}$. Serum 25(OH)D values cannot be compared directly because different assays were used. Of all participants, 25.1\% (first cohort) and $15.4 \%$ (second cohort) used four or more medicines.
Table 1 Characteristics of the whole study sample. Values are mean (s.D.), number (percentage) or median (interquartile range).

\begin{tabular}{|c|c|c|}
\hline & $1995 / 1996$ & $2002 / 2003$ \\
\hline$n$ & $1301(100)$ & $736(100)$ \\
\hline \multicolumn{3}{|l|}{ Gender } \\
\hline Male & $634(48.7)$ & 338 (45.9) \\
\hline Female & $667(51.3)$ & $398(54.1)$ \\
\hline Age (years) & $75.5(6.6)$ & $60(2.9)$ \\
\hline 25-Hydroxyvitamin D (nmol/l) & $53.4(24.1)$ & $56.7(20.7)$ \\
\hline Albumin (g/l) & $41.9(4.0)$ & $40.9(3.0)$ \\
\hline MDRD (ml/min per $\left.1.73 \mathrm{~m}^{2}\right)$ & $65.0(13.9)$ & $69.7(13.0)$ \\
\hline \multicolumn{3}{|l|}{ BMI $\left(\mathrm{kg} / \mathrm{m}^{2}\right)$} \\
\hline$<20$ (underweight) & $51(3.9)$ & $13(1.8)$ \\
\hline 20-25 (healthy weight) & $399(30.7)$ & $215(29.2)$ \\
\hline$>25$ (overweight) & $851(65.4)$ & $508(69.0)$ \\
\hline \multicolumn{3}{|l|}{ Smoker status } \\
\hline Never & 465 (35.7) & $177(24.0)$ \\
\hline Former & $598(46.0)$ & $359(48.8)$ \\
\hline \multirow{2}{*}{\multicolumn{3}{|c|}{ Alcohol consumption }} \\
\hline & & \\
\hline Non-drinker & $318(24.4)$ & $59(8.0)$ \\
\hline Light drinker & $653(50.2)$ & 341 (46.3) \\
\hline Moderate drinker & $251(19.3)$ & 257 (34.9) \\
\hline (Very) excessive drinker & $79(6.1)$ & 79 (10.7) \\
\hline \multicolumn{3}{|l|}{ Level of education } \\
\hline Low ( $\leq 9$ years) & $797(61.3)$ & $320(43.5)$ \\
\hline High ( $>9$ years) & $504(38.7)$ & $416(56.5)$ \\
\hline \multicolumn{3}{|l|}{ Season of blood collection } \\
\hline Winter & $721(55.4)$ & $650(88.3)$ \\
\hline Summer & $580(44.6)$ & $86(11.7)$ \\
\hline Chronic diseases $^{a}$ & $1.0(0-2)$ & $1.0(0-1)$ \\
\hline \multicolumn{3}{|l|}{ Number of medicines } \\
\hline None & $320(24.6)$ & $286(38.9)$ \\
\hline $1-3$ & $654(50.3)$ & $336(45.7)$ \\
\hline $4-6$ & $266(20.4)$ & $85(11.5)$ \\
\hline$>6$ & $61(4.7)$ & $29(3.9)$ \\
\hline Physical activity (min/day) & $149.2(97.4)$ & $167.5(105.6)$ \\
\hline
\end{tabular}

${ }^{a}$ Chronic diseases from seven majors: chronic obstructive pulmonary disease, cardiac disease, peripheral arterial disease, stroke, diabetes mellitus, rheumatoid arthritis/osteoarthritis and cancer.

Table 2 shows unadjusted mean values of serum $25(\mathrm{OH}) \mathrm{D}$ for users and non-users of several medication groups. Not all medication groups were analysed in both groups because we only performed an analysis when the user group consisted of $\geq 5 \%$ of the study population and because medication use differed between the two cohorts due to differences in date of measurement and in age of the participants. In general, the use of medicines was associated with lower serum 25(OH)D in comparison with non-use. Comparing the two cohorts, a higher use in proton pump inhibitors and statins and a lower use in digoxin, nitrates, coumarin derivatives, diuretics, benzodiazepines and $\mathrm{H}_{2}$-blockers were demonstrated in the second cohort compared with the first cohort.

Table 3 presents the results of linear regression analyses of the association between the use of several types of medication and serum 25(OH)D for the first cohort. A significant interaction with gender was found for coumarin derivatives, paracetamol and inhaled corticosteroids. Using any medicine was associated with a lower serum $25(\mathrm{OH}) \mathrm{D}$ in the fully adjusted 
Table 2 Unadjusted mean serum 25(OH)D for users and non-users of different medication groups.

\begin{tabular}{|c|c|c|c|c|c|c|}
\hline \multirow[b]{3}{*}{ Medication group } & \multicolumn{3}{|c|}{$1995 / 1996^{a}$} & \multicolumn{3}{|c|}{$2002 / 2003^{b}$} \\
\hline & \multirow[b]{2}{*}{$n$ (users) } & \multicolumn{2}{|c|}{ Serum 25(OH)D (s.D.; nmol/l) } & \multirow[b]{2}{*}{$n$ (users) } & \multicolumn{2}{|c|}{ Serum 25(OH)D (S.D.; nmol/l) } \\
\hline & & Users & Non-users & & Users & Non-users \\
\hline \multicolumn{7}{|l|}{ Any kind } \\
\hline Total & 981 & $51.4(24.0)$ & $59.5(23.4)$ & 451 & $x$ & $\mathrm{x}$ \\
\hline Men & 467 & $\mathrm{X}$ & $\mathrm{X}$ & 205 & $55.8(20.5)$ & $54.3(16.6)$ \\
\hline Women & 514 & $\mathrm{X}$ & $\mathrm{X}$ & 246 & $56.3(21.8)$ & $60.9(21.8)$ \\
\hline \multicolumn{7}{|l|}{ Coumarin derivatives } \\
\hline Total & 78 & $X$ & $\mathrm{X}$ & 18 & $\mathrm{X}$ & $\mathrm{X}$ \\
\hline Men & 55 & $58.9(24.9)$ & $58.0(24.4)$ & 9 & $X$ & $\mathrm{X}$ \\
\hline Women & 23 & $35.5(21.1)$ & $49.4(22.8)$ & 9 & $\mathrm{X}$ & $\mathrm{X}$ \\
\hline $\mathrm{H}_{2}$-blockers & 64 & $52.1(26.5)$ & $53.4(24.0)$ & 9 & $x$ & $\mathrm{x}$ \\
\hline Proton pump inhibitors & 36 & $\mathrm{X}$ & $\mathrm{X}$ & 54 & $51.6(17.2)$ & $57.1(20.9)$ \\
\hline Oral antidiabetics & 52 & $x$ & $\mathrm{X}$ & 36 & $48.2(19.4)$ & $57.1(20.7)$ \\
\hline Statins & 58 & $x$ & $\mathrm{X}$ & 95 & $52.7(18.7)$ & $57.3(20.9)$ \\
\hline Digoxin & 85 & $48.8(23.7)$ & $53.7(24.1)$ & 4 & $\mathrm{X}$ & $\mathrm{X}$ \\
\hline Nitrates & 115 & $49.8(23.2)$ & $53.7(24.2)$ & 18 & $x$ & $\mathrm{X}$ \\
\hline Calcium-channel blockers & 137 & $53.4(26.6)$ & $53.4(23.8)$ & 51 & $48.5(18.0)$ & $57.3(20.8)$ \\
\hline ACE inhibitors & 144 & $51.1(23.4)$ & $53.6(24.2)$ & 75 & $49.1(18.7)$ & $57.6(20.8)$ \\
\hline Thiazide diuretics & 161 & $49.4(24.0)$ & $53.9(24.1)$ & 64 & $53.9(23.4)$ & $57.0(20.4)$ \\
\hline Loop diuretics & 106 & $43.9(22.4)$ & $54.2(24.1)$ & 7 & $\mathrm{x}$ & $\mathrm{X}$ \\
\hline Potassium-sparing diuretics & 120 & 46.5 (22.7) & $54.1(24.1)$ & 14 & $\mathrm{X}$ & $\mathrm{x}$ \\
\hline Beta-blocking agents & 208 & $53.6(23.2)$ & $53.3(24.3)$ & 99 & $54.3(20.7)$ & $57.1(20.7)$ \\
\hline \multicolumn{7}{|l|}{ NSAIDs $^{c}$} \\
\hline Total & 355 & $50.8(23.6)$ & $54.3(24.2)$ & 135 & $\mathrm{X}$ & $\mathrm{X}$ \\
\hline Men & 170 & $\mathrm{X}$ & $\mathrm{X}$ & 70 & $56.3(22.5)$ & $54.9(18.2)$ \\
\hline Women & 185 & $x$ & $\mathrm{X}$ & 65 & $53.3(21.5)$ & $59.0(22.0)$ \\
\hline $\begin{array}{l}\text { Platelet aggregation } \\
\text { inhibitors }\end{array}$ & 240 & $50.4(23.2)$ & $54.0(24.3)$ & 77 & $54.3(19.5)$ & $57.0(20.8)$ \\
\hline Benzodiazepines & 183 & $46.3(23.4)$ & $54.5(24.0)$ & 54 & $52.7(22.7)$ & $57.1(20.5)$ \\
\hline \multicolumn{7}{|l|}{ Paracetamol } \\
\hline Total & 70 & $x$ & $\mathrm{X}$ & 19 & $\mathrm{X}$ & $\mathrm{X}$ \\
\hline Men & 18 & $43.5(25.7)$ & $58.5(24.3)$ & 5 & $\mathrm{X}$ & $x$ \\
\hline Women & 52 & $44.2(25.5)$ & $49.3(22.6)$ & 14 & $\mathrm{X}$ & $\mathrm{X}$ \\
\hline \multicolumn{7}{|l|}{ Inhaled corticosteroids } \\
\hline Total & 80 & $x$ & $x$ & 37 & $54.9(20.4)$ & $56.8(20.7)$ \\
\hline Men & 55 & $52.0(24.6)$ & $58.7(24.4)$ & 17 & $x$ & $\mathrm{x}$ \\
\hline Women & 25 & $53.4(27.3)$ & $48.7(22.7)$ & 20 & $x$ & $\mathrm{x}$ \\
\hline
\end{tabular}

Analysis was performed in subgroups (stratified by sex) if $P$ value for interaction term was $<0.1$.

${ }^{\text {a}}$ Total study sample: 1301 participants.

bTotal study sample: 737 participants.

${ }^{\mathrm{c}}$ Non-steroidal anti-inflammatory drugs.

model. In the analyses stratified for age, we only found a significant association in the oldest group (75 years and older; data not shown). For coumarin derivatives, only in women was a significant association (models 1 and 2) with serum 25(OH)D observed, while in model 3 the association became borderline significant. In the first and third models, loop diuretics were significantly associated with lower serum 25(OH)D. Only in men was the use of inhaled corticosteroids and paracetamol (in models 1 and 2) associated with lower serum 25(OH)D.

Table 4 presents the results of linear regression analyses of the association between the use of several types of medication and serum $25(\mathrm{OH}) \mathrm{D}$ for the second cohort. A significant interaction for gender was found for the use of any kind of medicine and non-steroidal anti-inflammatory drug (NSAID). A significant association between the use of any medicine and lower serum $25(\mathrm{OH}) \mathrm{D}$ was found, but only for women in the first model. In the second model the association became borderline significant. A borderline significant association between the use of proton pump inhibitors and lower serum 25(OH)D was observed in the fully adjusted model. The associations between oral antidiabetics, calcium-channel blockers and angiotensin-converting enzyme (ACE) inhibitors and lower serum 25(OH)D were significant in the fully adjusted model. We did not observe any significant relationship between statin use and serum 25(OH)D.

Figure 1 presents the relation between the number of medicines and serum 25(OH)D. In both cohorts the number of medicines was negatively associated with serum $25(\mathrm{OH}) \mathrm{D}$ (first cohort: $B=-0.7, P<0.01$; second cohort: $B=-1.1, P<0.01)$, after adjustment for confounding.

The addition of multi-vitamin use to the models did not materially change the results. After the addition 
Table 3 Results of multiple linear regression analysis of associations between medication use and serum 25-hydroxyvitamin $D$ in the first cohort (1995/1996). Data are expressed as regression coefficient ( $\beta ; 95 \%$ confidence intervals).

\begin{tabular}{|c|c|c|c|c|c|c|}
\hline & \multicolumn{2}{|c|}{ Model $1^{a}$} & \multicolumn{2}{|c|}{ Model $2^{b}$} & \multicolumn{2}{|l|}{ Model $3^{c}$} \\
\hline & $\beta(95 \% \mathrm{Cl})$ & $P$ value & $\beta(95 \% \mathrm{Cl})$ & $P$ value & $\beta(95 \% \mathrm{Cl})$ & $P$ value \\
\hline $\begin{array}{l}\text { Any kind } \\
\text { Coumarin derivatives }\end{array}$ & $-4.4(-7.2 ;-1.5)$ & $<0.01$ & $-3.5(-6.5 ;-0.5)$ & 0.02 & $-4.2(-7.0 ;-1.3)$ & $<0.01$ \\
\hline Men & $-0.3(-6.7 ; 6.0)$ & 0.92 & $1.5(-5.1 ; 8.3)$ & 0.65 & $1.6(-4.8 ; 8.1)$ & 0.62 \\
\hline Women & $-12.2(-21.0 ;-3.4)$ & $<0.01$ & $-10.5(-19.5 ;-1.4)$ & 0.02 & $-8.6(-17.3 ; 0.1)$ & 0.05 \\
\hline $\mathrm{H}_{2}$-blockers & $-0.6(-6.1 ; 5.0)$ & 0.83 & $0.0(-5.5 ; 5.6)$ & 0.99 & $0.3(-5.0 ; 5.6)$ & 0.90 \\
\hline Digoxin & $-0.1(-5.1 ; 4.8)$ & 0.96 & $1.3(-3.8 ; 6.3)$ & 0.62 & $0.5(-4.3 ; 5.3)$ & 0.84 \\
\hline Nitrates & $1.0(-5.3 ; 3.3)$ & 0.66 & $0.4(-3.9 ; 4.9)$ & 0.84 & $0.1(-4.1 ; 4.3)$ & 0.96 \\
\hline Calcium-channel blockers & $2.6(-1.3 ; 6.6)$ & 0.19 & $3.8(-0.2 ; 7.8)$ & 0.07 & $2.9(-0.9 ; 6.8)$ & 0.13 \\
\hline ACE inhibitors & $-2.6(-6.4 ; 1.2)$ & 0.19 & $-1.7(-5.6 ; 2.1)$ & 0.38 & $-2.7(-6.4 ; 1.0)$ & 0.15 \\
\hline Thiazide diuretics & $-1.1(-4.8 ; 2.6)$ & 0.57 & $-1.0(-4.6 ; 2.7)$ & 0.61 & $-0.7(-4.2 ; 2.8)$ & 0.67 \\
\hline Loop diuretics & $-4.5(-8.9 ; 0.0)$ & 0.05 & $-3.5(-8.0 ; 1.0)$ & 0.13 & $-4.7(-9.0 ;-0.3)$ & 0.04 \\
\hline Potassium-sparing diuretics & $-2.3(-6.5 ; 1.9)$ & 0.29 & $-2.0(-6.2 ; 2.2)$ & 0.35 & $-2.0(-6.0 ; 2.0)$ & 0.32 \\
\hline Beta-blocking agents & $0.0(-3.3 ; 3.3)$ & 0.99 & $0.6(-2.7 ; 3.9)$ & 0.71 & $0.4(-2.8 ; 3.6)$ & 0.80 \\
\hline NSAIDs $^{d}$ & $-1.0(-3.7 ; 1.7)$ & 0.46 & $-0.2(-3.0 ; 2.5)$ & 0.87 & $-0.7(-3.3 ; 2.0)$ & 0.62 \\
\hline Platelet aggregation blockers & $-1.2(-4.3 ; 2.0)$ & 0.47 & $-0.3(-3.5 ; 2.9)$ & 0.87 & $-1.1(-4.2 ; 1.9)$ & 0.48 \\
\hline Benzodiazepines & $-3.7(-7.2 ;-0.1)$ & 0.04 & $-3.0(-6.6 ; 0.5)$ & 0.09 & $-2.8(-6.2 ; 0.6)$ & 0.10 \\
\hline \multicolumn{7}{|l|}{ Paracetamol } \\
\hline Men & $-11.7(-22.5 ;-1.0)$ & 0.03 & $-10.8(-21.6 ; 0.0)$ & 0.05 & $-7.4(-17.4 ; 3.0)$ & 0.16 \\
\hline Women & $-2.0(-8.1 ; 4.0)$ & 0.51 & $-1.1(-7.2 ; 5.0)$ & 0.73 & $0.2(-5.7 ; 6.1)$ & 0.95 \\
\hline \multicolumn{7}{|l|}{ Inhaled corticosteroids } \\
\hline Men & $-6.5(-12.8 ;-0.2)$ & 0.05 & $-5.5(-12.0 ; 1.1)$ & 0.10 & $-7.3(-13.7 ;-1.0)$ & 0.02 \\
\hline Women & $2.7(-5.8 ; 11.2)$ & 0.53 & $4.1(-4.4 ; 12.7)$ & 0.34 & $4.8(-3.4 ; 13.0)$ & 0.25 \\
\hline
\end{tabular}

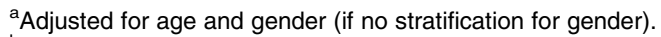

${ }^{\mathrm{b}}$ Adjusted for age, gender (if no stratification for gender), and number of chronic diseases.

${ }^{\mathrm{c} A d j u s t e d}$ for age, gender (if no stratification for gender), number of chronic diseases, BMI, MDRD, albumin, smoking, alcohol use and season of blood collection.

${ }^{\mathrm{d}}$ Non-steroidal anti-inflammatory drugs.

Statistically significant $P$ values are in boldface.

of physical activity, only the $B$ of the use of oral antidiabetics with $25(\mathrm{OH}) \mathrm{D}$ in the second cohort changed from -7.3 to -6.9 ( $P=0.06$; data not shown).

\section{Discussion}

In this study, we examined associations between specific medicines and serum 25(OH)D. In the first cohort, aged 65 years and older, associations with lower serum $25(\mathrm{OH}) \mathrm{D}$ were observed in individuals who used any medication, loop diuretics or inhaled corticosteroids (only in men). In the second cohort, aged 55-65 years, associations with lower serum 25(OH)D were found in individuals using oral antidiabetics, calcium-channel blockers or ACE inhibitors. To our knowledge, these associations have not been investigated before. The addition of physical activity to the models did not change the results significantly. This indicates that physical activity is neither a relevant confounder nor a mediator in the relationship between medication use and vitamin D status. We question the possible causes of lower serum 25(OH)D in the user group, but due to study design no inference can be made about causality. However, three causes have to be considered. First, it could be the medicines themselves. Second, chronic diseases leading to medication use could contribute to lower levels (confounding by indication). And finally, a (chronic) disease might be a consequence of vitamin D deficiency.

In the first cohort, the use of any medication was associated with lower serum 25(OH)D. When analysing in subgroups (divided by the median age, 75 years), the association was only significant in the oldest group. This is in accordance with the results of the second cohort, which consisted of younger persons and in which we found no association. Also the number of medicines used was associated with lower serum 25(OH)D. To our knowledge, these associations were demonstrated for the first time. It is impossible to speculate on the cause of this relationship because of the diversity of medicines used. Medication use may be considered as a manifestation of frailty in older individuals, which Lang et al. (18) also suggest.

Our findings regarding the association of loop diuretic use and lower serum 25(OH)D are in accordance with previous research by Rejnmark et al. (19), although the significant association that they observed disappeared after adjustment for confounding. Adjustment for confounding was slightly different compared with our study. For example, no correction for chronic diseases was performed in that study, on the other hand the use of vitamin D supplements was taken into account (19). Unfortunately, over-the-counter vitamin D use was not available in our study. The sensitivity analysis which added multi-vitamin use, however, did not change our 
Table 4 Results of multiple linear regression analysis of associations between medication use and serum 25(OH)D in the second cohort (2002/2003). Data are expressed as regression coefficient ( $\beta ; 95 \%$ confidence intervals).

\begin{tabular}{|c|c|c|c|c|c|c|}
\hline & \multicolumn{2}{|c|}{ Model $1^{a}$} & \multicolumn{2}{|c|}{ Model $2^{b}$} & \multicolumn{2}{|l|}{ Model $3^{c}$} \\
\hline & $\beta(95 \% \mathrm{Cl})$ & $P$ value & $\beta(95 \% \mathrm{Cl})$ & $P$ value & $\beta(95 \% \mathrm{Cl})$ & $P$ value \\
\hline \multicolumn{7}{|l|}{ Any kind } \\
\hline Men & $1.2(-3.0 ; 5.5)$ & 0.56 & $2.9(-1.6 ; 7.5)$ & 0.21 & $3.0(-1.5 ; 7.5)$ & 0.20 \\
\hline Women & $-4.4(-8.9 ; 0.0)$ & 0.05 & $-4.4(-9.0 ; 0.3)$ & 0.07 & $-3.4(-8.1 ; 1.2)$ & 0.14 \\
\hline Proton pump inhibitors & $-5.6(-11.3 ; 0.1)$ & 0.06 & $-5.2(-11.0 ; 0.5)$ & 0.07 & $-5.4(-11.1 ; 0.2)$ & 0.06 \\
\hline Oral antidiabetics & $-8.6(-15.5 ;-1.7)$ & 0.02 & $-7.7(-14.8 ;-0.5)$ & 0.04 & $-7.3(-14.4 ;-0.3)$ & 0.04 \\
\hline Platelet aggregation inhibitors & $-1.7(-6.6 ; 3.3)$ & 0.51 & $-0.3(-5.6 ; 5.0)$ & 0.91 & $-0.7(-6.0 ; 4.4)$ & 0.77 \\
\hline Statins & $-4.2(-8.7 ; 0.3)$ & 0.07 & $-3.4(-8.1 ; 1.4)$ & 0.17 & $-3.4(-8.0 ; 1.3)$ & 0.16 \\
\hline Calcium-channel blockers & $-7.8(-13.8 ;-1.9)$ & 0.01 & $-7.2(-13.2 ;-1.1)$ & 0.02 & $-7.7(-13.6 ;-1.7)$ & 0.01 \\
\hline ACE inhibitors & $-7.8(-12.7 ;-2.8)$ & $<0.01$ & $-7.4(-12.4 ;-2.3)$ & $<0.01$ & $-7.6(-12.5 ;-2.7)$ & $<0.01$ \\
\hline Thiazide diuretics & $-3.2(-8.5 ; 2.1)$ & 0.23 & $-2.8(-8.2 ; 2.5)$ & 0.30 & $-3.8(-9.0 ; 1.5)$ & 0.16 \\
\hline Beta-blocking agents & $-2.5(-6.9 ; 1.8)$ & 0.26 & $-2.1(-6.5 ; 2.4)$ & 0.36 & $-2.0(-6.4 ; 2.4)$ & 0.37 \\
\hline \multicolumn{7}{|l|}{ NSAIDs $^{d}$} \\
\hline Men & $1.3(-3.8 ; 6.3)$ & 0.62 & $3.9(-1.8 ; 9.5)$ & 0.18 & $3.1(-2.5 ; 8.7)$ & 0.27 \\
\hline Women & $-5.5(-11.3 ; 0.3)$ & 0.06 & $-5.3(-11.3 ; 0.7)$ & 0.08 & $-4.0(-9.9 ; 1.9)$ & 0.19 \\
\hline Benzodiazepines & $-5.2(-11.1 ; 0.6)$ & 0.08 & $-4.7(-10.6 ; 1.2)$ & 0.12 & $-2.4(-8.2 ; 3.4)$ & 0.42 \\
\hline Inhaled corticosteroids & $-1.8(-8.6 ; 5.0)$ & 0.61 & $-0.5(-7.5 ; 6.6)$ & 0.89 & $-0.5(-7.4 ; 6.4)$ & 0.89 \\
\hline
\end{tabular}

${ }^{a}$ Adjusted for age and gender (if no stratification for gender).

${ }^{\mathrm{b}}$ Adjusted for age, gender (if no stratification for gender) and number of chronic diseases.

${ }^{\mathrm{c} A d j u s t e d ~ f o r ~ a g e, ~ g e n d e r ~(i f ~ n o ~ s t r a t i f i c a t i o n ~ f o r ~ g e n d e r), ~ n u m b e r ~ o f ~ c h r o n i c ~ d i s e a s e s, ~ B M I, ~ M D R D, ~ a l b u m i n, ~ s m o k i n g, ~ a l c o h o l ~ u s e, ~ a n d ~ s e a s o n ~ o f ~ b l o o d ~}$ collection.

${ }^{\mathrm{d}}$ Non-steroidal anti-inflammatory drugs.

results. A randomised clinical trial showed an increase in serum PTH and serum $1,25(\mathrm{OH})_{2} \mathrm{D}$ after 7 days of loop diuretic use compared with placebo (20). Loop diuretics increase renal calcium excretion, causing secondary hyperparathyroidism. Hyperparathyroidism causes an increased hydroxylation of $25(\mathrm{OH}) \mathrm{D}$ into $1,25(\mathrm{OH})_{2} \mathrm{D}$, which results in higher levels of $1,25(\mathrm{OH})_{2} \mathrm{D}(19,20)$. The increased conversion might partly explain the decreased level of $25(\mathrm{OH}) \mathrm{D}$ within the user population. In addition, an increased catabolism of serum 25(OH)D stimulated by higher levels of $1,25(\mathrm{OH})_{2} \mathrm{D}$ could contribute to a lower serum 25(OH)D (21). In the present study we did not measure $1,25(\mathrm{OH})_{2} \mathrm{D}$. In the second cohort, loop diuretic use was much lower and the association with $25(\mathrm{OH}) \mathrm{D}$ could not be studied.

Previous research found no effect of inhaled glucocorticosteroids on serum 25(OH)D (22). The findings in our second cohort are in line with this research. However, in the first cohort we did observe a significant association with lower serum 25(OH)D in men. Vitamin D deficiency is highly prevalent in chronic obstructive pulmonary disease (for which inhaled corticosteroids are mainly used), and serum levels correlate with severity of this disease $(23,24)$. Confounding by indication may indeed contribute to the association between inhaled corticosteroid use and lower serum 25(OH)D.

Vitamin D deficiency is associated with increased insulin resistance and decreased insulin secretion $(25$, 26). In our second study cohort, mean serum $25(\mathrm{OH}) \mathrm{D}$ of users of oral antidiabetics was $7.3 \mathrm{nmol} / \mathrm{l}$ lower compared with non-users. Although addition of physical activity to the model leads to a non-significant $P$ value, the absolute difference in $25(\mathrm{OH}) \mathrm{D}$ levels did not alter materially between users and non-users of oral antidiabetics and thus the clinical relevance will be comparable. Whether this difference is caused by the medication or by the diabetes should be the subject of further study.

Calcium-channel blocker use resulted in $7.7 \mathrm{nmol} / \mathrm{l}$ lower serum 25(OH)D compared with non-use. The mechanism at work might be found in the metabolism of vitamin D. Precursors of $25(\mathrm{OH}) \mathrm{D}$ are formed in the skin under the influence of u.v. light and some nutrients also contain these precursors $(1,26)$. These precursors are hydroxylated in the liver into $25(\mathrm{OH}) \mathrm{D}$ by 25-hydroxylases of cytochrome $\mathrm{P} 450$ isoenzymes, like CYP27A1, CYP2R1, CYP3A4 and CYPJ3. As calciumchannel blockers act as an inhibitor of CYP3A4, the formation of 25(OH)D may decrease, resulting in lower serum 25(OH)D $(26,27,28)$.

ACE inhibitor use resulted in $7.6 \mathrm{nmol} / \mathrm{l}$ lower serum $25(\mathrm{OH}) \mathrm{D}$ compared with non-use. Indications for ACE inhibitor use are heart failure and hypertension in patients with metabolic syndrome and diabetes $(29,30)$. Hypertension may be associated with lower serum 25(OH)D (31). However, in LASA no associations between blood pressure and hypertension and serum 25(OH)D were found (32). Some other epidemiological studies showed associations between low serum 25(OH)D and several cardiovascular outcomes, but evidence for a causal relationship is lacking. The results of a systematic review and meta-analysis were equivocal (33). However, mechanistic explanations are available (34). Studies with vitamin D receptor null mice concluded that absence of effect of $1,25(\mathrm{OH})_{2} \mathrm{D}$ is involved in the development of hypertension. Serum $1,25(\mathrm{OH})_{2} \mathrm{D}$ inhibits the production of renin, which is 

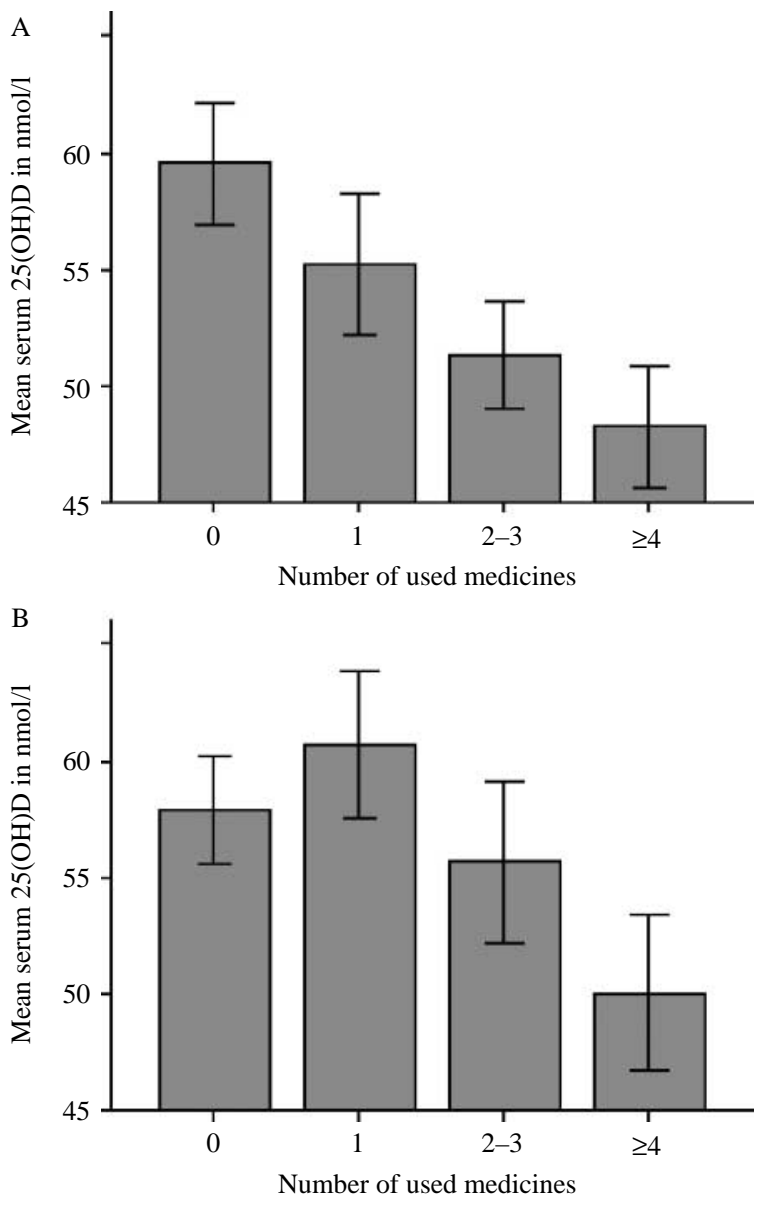

Figure 1 Mean serum 25(OH)D (in nmol/l), with 95\% confidence intervals, plotted against number of used medicines. Users of medicines are divided into three groups according to tertiles. (A) First cohort (1995/1996) and (B) second cohort (2002/2003).

involved in the regulation of electrolyte, volume and blood pressure homeostasis (34). Despite these mechanistic explanations, a causal relationship between vitamin $\mathrm{D}$ status and hypertension has not been confirmed in clinical trials so far (33). Whether the observed difference in serum $25(\mathrm{OH}) \mathrm{D}$ was caused by the medication or by hypertension and cardiovascular disease or by coincidence should be the subject of further research.

Proton pump inhibitor use was associated with $5.4 \mathrm{nmol} / \mathrm{l}$ lower serum $25(\mathrm{OH}) \mathrm{D}$, although it should be considered as borderline significant. The first cohort only contained few users and thus, analyses could not be performed. Proton pump inhibitors are associated with increased risk of osteoporotic fractures (35). However, information about the relationship with serum $25(\mathrm{OH}) \mathrm{D}$ is limited. Recently published research showed no change in serum 25(OH)D after omeprazol therapy, but this study sample consisted of healthy young people and they used omeprazole for only 30 days (36).

Definite conclusions regarding potential relationships between the use of coumarin derivatives and paracetamol and serum $25(\mathrm{OH}) \mathrm{D}$ cannot be made on the basis of our study because only a very small part of the study population used these drugs.

Previous studies reported different results about the association between statin use and serum 25(OH)D. Rosuvastatin $(6,8)$ and atorvastatin $(7)$ were found to increase serum levels, whereas fluvastatin and simvastatin did not change these levels significantly $(6,37)$. We observed no significant association between statin use and serum 25(OH)D. In the first cohort we performed the same analysis, despite the user group being less than $5 \%$ of the population. We too did not observe an association (data not shown). Most of our participants used simvastatin $(93 \%$ in first cohort and $51 \%$ in second cohort). Thus, a change in serum 25(OH)D was not expected.

Differences in used medicines are mainly due to different time points between the two cohorts (1995/1996 vs 2002/2003) and due to age differences (mean age 75 years vs 60 years). Prescription of medicines changed a little in the period between the cohorts. Age differences may contribute to differences in effects of several medicines. It is likely that older persons will react differently to medication.

The main limitation of this study is that we could not exclude confounding by indication. Pragmatically, we adjusted for the number of chronic diseases. Furthermore, it was not possible to consider vitamin D intake because information about over-the-counter vitamin D use or diet was not assessed. A sensitivity analysis however, in which multi-vitamin use was added to the models, showed no differences in observed associations. We also realise that we could not investigate the association for one specific medicine separately because most participants did not use only one kind of medicine. The LASA population is a representative sample of the Dutch older population and this also pertains to the use of medicines. Lastly, although we tested many medication groups, we do not think that the results represent a type 1 error because the significant $P$ values were low. The strengths of our study include the population-based design, the large study population with a wide age range and accuracy in reporting medication use.

Our study results show interesting associations between several types of medicines and serum $25(\mathrm{OH}) \mathrm{D}$. Nevertheless, further studies are necessary to confirm our findings and to explore potential underlying mechanisms. Additionally, an increasing number of medicines are associated with lower serum 25(OH)D levels. This suggests that vitamin D supplementation should be considered in patients with chronic use of more than one medication.

\section{Declaration of interest}

The authors declare that there is no conflict of interest that could be perceived as prejudicing the impartiality of the research reported. 


\section{Funding}

This study is based on data from The Longitudinal Aging Study Amsterdam, which is largely supported by a grant from the Netherlands Ministry of Health, Welfare and Sports, Directorate of Long-Term Care. In addition, this study was partly funded by ZonMw. The serum 25(OH)D measurements of the second cohort were funded by Merck \& Co.

\section{References}

1 Lips P. Vitamin D deficiency and secondary hyperparathyroidism in the elderly: consequences for bone loss and fractures and therapeutic implications. Endocrine Reviews 200122 477-501. (doi:10.1210/er.22.4.477)

2 van Schoor NM, Visser M, Pluijm SMF, Kuchuk N, Smit JH \& Lips P. Vitamin D deficiency as a risk factor for osteoporotic fractures. Bone 200842 260-266. (doi:10.1016/j.bone.2007.11.002)

3 Christensen K, Doblhammer G, Rau R \& Vaupel JW. Ageing populations: the challenges ahead. Lancet 2009374 1196-1208. (doi:10.1016/S0140-6736(09)61460-4)

4 Kaufman DW, Kelly JP, Rosenberg L, Anderson TE \& Mitchell AA. Recent patterns of medication use in the ambulatory adult population of the United States: the Slone survey. Journal of the American Medical Association 2002287 337-344. (doi:10.1001/ jama.287.3.337)

5 SFK. Facts and Figs 2010: 2009 in numbers. Foundation for Pharmaceutical Statistics - Website. (cited 2011, June 8). Available from URL: http://www.sfk.nl/publicaties/algemeen/english.html.

6 Ertugrul D, Yavuz B, Cil H, Ata N, Akin K, Kucukazman M, Yalcin A, Dal K, Yavuz B \& Tutal E. STATIN-D study: comparison of the influences of rosuvastatin and fluvastatin treatment on the levels of 25 hydroxyvitamin D. Cardiovascular Therapeutics 201129 146-152. (doi:10.1111/j.1755-5922.2010.00141.x)

7 Sathyapalan T, Shepherd J, Arnett C, Coady AM, Kilpatrick ES \& Atkin SL. Atorvastatin increases 25-hydroxy vitamin D concentrations in patients with polycystic ovary syndrome. Clinical Chemistry 201056 1696-1700. (doi:10.1373/clinchem.2010. 144014)

8 Yavuz B, Ertugrul DT, Cil H, Ata N, Akin KO, Yalcin AA, Kucukazman M, Dal K, Hokkaomeroglu MS, Yavuz BB \& Tutal E. Increased levels of 25 hydroxyvitamin D and 1,25-dihydroxyvitamin D after rosuvastatin treatment: a novel pleiotropic effect of statins? Cardiovascular Drugs and Therapy 200923 295-299. (doi:10.1007/s10557-009-6181-8)

9 Kulak CAM, Borba VZC, Bilezikian JP, Silvado CE, Paola LD \& Boguszewski CL. Bone mineral density and serum levels of $25 \mathrm{OH}$ vitamin $\mathrm{D}$ in chronic users of antiepileptic drugs. Arquivos de Neuro-Psiquiatria 200462 940-948. (doi:10.1590/S0004282X2004000600003)

10 Misra A, Aggarwal A, Singh O \& Sharma S. Effect of carbamazepine therapy on vitamin D and parathormone in epileptic children. Pediatric Neurology $2010 \quad 43 \quad 320-324$. (doi:10.1016/j.pediatrneurol.2010.05.013)

11 Deeg DJH, van Tilburg T, Smit JH \& de Leeuw ED. Attrition in the Longitudinal Aging Study Amsterdam. The effect of differential inclusion in side studies. Journal of Clinical Epidemiology 200255 319-328. (doi:10.1016/S0895-4356(01)00475-9)

12 Huisman M, Poppelaars J, van der Horst M, Beekman A, Brug J, van Tilburg T \& Deeg D. Cohort profile: the Longitudinal Aging Study Amsterdam. International Journal of Epidemiology $2011 \mathbf{4 0}$ 868-876. (doi:10.1093/ije/dyq219)

13 WHO collaborating Centre for drug Statistics Methodology - Website (cited 2011, April 27); Available from URL: http://www. whocc.no/atc_ddd_index/.

14 Freire AC, Basit AW, Choudhary R, Piong CW \& Merchant HA. Does sex matter? The influence of gender on gastrointestinal physiology and drug delivery. International Journal of Pharmaceutics 2011415 15-28. (doi:10.1016/j.ijpharm.2011.04.069)
15 Garretsen HFL. In Probleemdrinken, Prevalentiebepaling, Beinvloedende Factoren en Preventiemogelijkheden, Theoretische Overwegingen en Onderzoek in Rotterdam (dissertation in Dutch). Lisse, The Netherlands: Swets and Zeitlinger, 1983.

16 Manjunath G, Sarnak MJ \& Levey AS. Prediction equations to estimate glomerular filtration rate: an update. Current Opinion in Nephrology and Hypertension 200110 785-792. (doi:10.1097/ 00041552-200111000-00009)

17 Stel VS, Smit JH, Pluijm SMF, Visser M, Deeg DJH \& Lips P. Comparison of the LASA Physical Activity Questionnaire with a 7-day diary and pedometer. Journal of Clinical Epidemiology 2004 57 252-258. (doi:10.1016/j.jclinepi.2003.07.008)

18 Lang PO, Michel JP \& Zekry D. Frailty syndrome: a transitional state in a dynamic process. Gerontology 200955 539-549. (doi:10.1159/000211949)

19 Rejnmark L, Vestergaard P, Heickendorff L, Andreasen F \& Mosekilde L. Effects of long-term treatment with loop diuretics on bone mineral density, calcitropic hormones and bone turnover. Journal of Internal Medicine 2005257 176-184. (doi:10.1111/j. 1365-2796.2004.01434.x)

20 Rejnmark L, Vestergaard P, Heickendorff L, Andreasen F \& Mosekilde L. Effects of thiazide- and loop-diuretics, alone or in combination, on calcitropic hormones and biochemical bone markers: a randomized controlled study. Journal of Internal Medicine 2001250 144-153. (doi:10.1046/j.1365-2796.2001. 00868.x)

21 Mikhail N. Clinical significance of vitamin D deficiency in primary hyperparathyroidism, and safety of vitamin D therapy. Southern Medical Journal 2011104 29-33. (doi:10.1097/SMJ. Ob013e3181fcd772)

22 Jennings BH, Andersson KE \& Johansson SA. The assessment of the systemic effects of inhaled glucocorticosteroids. The effects of inhaled budesonide vs oral prednisolone on calcium metabolism. European Journal of Clinical Pharmacology 1991 41 11-16. (doi:10. 1007/BF00280099)

23 Janssens W, Bouillon R, Claes B, Carremans C, Lehouck A, Buysschaert I, Coolen J, Mathieu C, Decramer M \& Lambrechts D. Vitamin D deficiency is highly prevalent in COPD and correlates with variants in the vitamin D-binding gene. Thorax 201065 215-220. (doi:10.1136/thx.2009.120659)

24 Kunisaki KM \& Rector TS. Vitamin D and responses to inhaled fluticasone in severe chronic obstructive pulmonary disease. International Journal of Chronic Obstructive Pulmonary Disease 20116 29-34. (doi:10.2147/COPD.S15358)

25 Boucher BJ. Inadequate vitamin D status: does it contribute to the disorders comprising syndrome ' $\mathrm{X}$ '? British Journal of Nutrition 199879 315-327. (doi:10.1079/BJN19980055)

26 Takiishi T, Gysemans C, Bouillon R \& Mathieu C. Vitamin D and diabetes. Endocrinology and Metabolism Clinics of North America 201039 419-446. (doi:10.1016/j.ecl.2010.02.013)

27 Zhou SF. Drugs behave as substrates, inhibitors and inducers of human cytochrome P450 3A4. Current Drug Metabolism 20089 310-322. (doi:10.2174/138920008784220664)

28 Levin TT, Bakr MH \& Nikolova T. Case report: delirium due to a diltiazem-fentanyl CYP3A4 drug interaction. General Hospital Psychiatry 201032 648. (doi:10.1016/j.genhosppsych.2010. 08.003)

29 McFarlane SI, Kumar A \& Sowers JR. Mechanisms by which angiotensin-converting enzyme inhibitors prevent diabetes and cardiovascular disease. American Journal of Cardiology 200391 30H-37H. (doi:10.1016/SOO02-9149(03)00432-6)

30 Werner C, Baumhakel M, Teo KK, Schmieder R, Mann J, Unger T, Yusuf S \& Bohm M. RAS blockade with ARB and ACE inhibitors: current perspective on rationale and patient selection. Clinical Research in Cardiology 200897 418-431. (doi:10.1007/s00392008-0668-3)

31 Feneis JF \& Arora RR. Role of vitamin D in blood pressure homeostasis. American Journal of Therapeutics $2010 \quad \mathbf{1 7}$ e221-e229. (doi:10.1097/MJT.0b013e3181d16999)

32 Snijder MB, Lips P, Seidell JC, Visser M, Deeg DJH, Dekker JM \& van Dam RM. Vitamin D status and parathyroid hormone levels 
in relation to blood pressure: a population-based study in older men and women. Journal of Internal Medicine $2007261558-565$. (doi:10.1111/j.1365-2796.2007.01778.x)

33 Pittas AG, Chung M, Trikalinos T, Mitri J, Brendel M, Patel K, Lichtenstein AH, Lau J \& Balk EM. Systematic review: vitamin D and cardiometabolic outcomes. Annals of Internal Medicine 2010 152 307-314.

34 Bouillon R, Carmeliet G, Verlinden L, van Etten E, Verstuyf A, Luderer HF, Lieben L, Mathieu C \& Demay M. Vitamin D and human health: lessons from vitamin D receptor null mice. Endocrine Reviews 200829 726-776. (doi:10.1210/er.2008-0004)

35 Targownik LE, Lix LM, Metge CJ, Prior HJ, Leung S \& Leslie WD. Use of proton pump inhibitors and risk of osteoporosis-related fractures. Canadian Medical Association Journal $2008 \mathbf{1 7 9}$ 319-326. (doi:10.1503/cmaj.071330)
36 Hansen KE, Jones AN, Lindstrom MJ, Davis LA, Ziegler TE, Penniston KL, Alvig AL \& Shafer MM. Do proton pump inhibitors decrease calcium absorption? Journal of Bone and Mineral Research 201025 2786-2795. (doi:10.1002/jbmr.166)

37 Rejnmark L, Vestergaard P, Heickendorff L \& Mosekilde L. Simvastatin does not affect vitamin D status, but low vitamin D levels are associated with dyslipidemia: results from a randomised, controlled trial. International Journal of Endocrinology $2010 \mathbf{2 0 1 0}$ 957174. (doi:10.1155/2010/957174)

Received 25 October 2011

Revised version received 5 December 2011

Accepted 14 December 2011 